\title{
Removal of Methylene Blue by Adsorption of Water Hyacinth Derived Active Carbon Embedded with Cobalt Nanoparticles
}

\author{
Hany A. Elazab ${ }^{1,2, *(D)}$, A. O. Okasha ${ }^{1}$, M. A. Radwan ${ }^{1}$, M. A. Sadek ${ }^{1}$, Amin Firouzi ${ }^{3}$, \\ Tamer T. El-Idreesy ${ }^{4,5}, *$ (D)
}

1 Department of Chemical Engineering, Faculty of Engineering, The British University in Egypt, El-Shorouk City, Cairo, Egypt

2 Nanotechnology Research Centre (NTRC), the British University in Egypt (BUE), El-Sherouk City, Suez Desert Road, Cairo, 11837, Egypt.; elazabha@vcu.edu (H.A.E.);

3 Department of Biomedical Engineering, University of Houston, Houston, TX, 77204, US

4 Department of Chemistry, Faculty of Science, Cairo University, Giza 12613, Egypt.; tamer@cu.edu.eg (T.T.E-I.);

5 Department of Chemistry, School of Sciences and Engineering, The American University in Cairo, New Cairo 11835, Egypt

* Correspondence: elazabha@vcu.edu (H.A.E.); tamer@cu.edu.eg (T.T.E-I.);

Scopus Author ID 57197864132 (H.A.E.); 6507120225 (T.T.E-I.)

Received: 20.01.2021; Revised: 30.03.2021; Accepted: 5.04.2021; Published: 7.05.2021

\begin{abstract}
In this research, active carbon-based catalyst synthesis and characterization were tested for potential catalysts to be used in dye removal of methylene blue (MB). Water hyacinth is one of the major problems that is facing humankind and especially here in Egypt. One of the implications of industrial activities is environmental pollution. Dyes used in the production of textiles, paper, and clothes are one of the major pollutants. The waste of those dyes discharged into water supplies without treatment or with ineffective treatment harmfully impacts the environment. In this research, the treatment is implemented using active carbon-based catalysts using embedded nanoparticles. This leads to a huge increase in the adsorbent's surface area, also increasing the adsorbent efficiency. The activated carbon was derived from water hyacinth that grows near the Nile River. Water hyacinth has many practical uses as it can absorb heavy metals like lead and dyes. Water hyacinth was converted into activated carbon through carbonization. Different dyes were used with different contact times in fixed conditions.
\end{abstract}

Keywords: dye removal; metal oxides; catalyst; wastewater treatment; active carbon; water hyacinth.

(C) 2021 by the authors. This article is an open-access article distributed under the terms and conditions of the Creative Commons Attribution (CC BY) license (https://creativecommons.org/licenses/by/4.0/).

\section{Introduction}

Industrial pollution is more dangerous than the generation of power. Industrial dye waste must be treated well not to affect the water and aquatic life [1-5]. Then, chemical engineers and chemistry scientists cooperate in several research pieces to figure out easy and applicable ways to treat the water with organic and synthetic compounds. Dyes are substances used to add color to several things, such as textiles, papers, leather, and other materials. Like that, the coloring is not changed or impacted by washing, light, heat, or any other factor to which the colored material may be exposed. Dyes are different from pigments, which are finely ground solids dispersed in a liquid, such as paint or ink, or blended with other materials [6-14]. 
Most dyes are organic compounds that contain carbon, but pigments may be inorganic and do not contain carbon or organic compounds.

Water pollution is a serious issue, where dye ions from dyeing industries have been emerged as a severe threat to human beings and the aquatic ecosystem due to their toxicity and persistence after being released in natural water. Therefore, discharge regulations are progressively becoming more stringent [15-22]. Many recent studies have been focused on developing efficient processes for the recovery of these organic contaminants from the effluents of textile industries. Usually, conventional techniques such as precipitation, coagulation, and flocculation have been used in wastewater treatment. Photo-oxidation has also been proposed for the treatment of dye-containing effluents. However, this process is relatively expensive and not appropriate for the treatment of large flows. Biological degradation has been cited as an alternative process for decolorizing the reactive dye [7-9, 23-26].

On the other hand, the adsorption process remains the most common and useful technique for the decontamination of the effluents of textile and dyeing industries. Many studies have been made on the possibility of adsorbents using mineral sorbents, activated carbon, peat, rice husk, soy meal hull, and agro wastes. However, the adsorption capacity of the adsorbents is not very effective in improving adsorption performance, and new adsorbents are still under development [27-30]. The attention has been placed on understanding kinetics, mechanisms, and equilibrium processes involved in the adsorption of MB onto chitosan. The effects of $\mathrm{pH}$, initial dye concentration, and adsorbent dosages on the adsorption phenomena have been studied. Methylene blue, also known as methylthioninium chloride, is a medication and dye [15-22, 31-36]. Many industries' effluent water, such as textiles, leather, paper, printing, cosmetics, etc., contains a large amount of hazardous dye. After colorization, it is disposed of as waste with water then going to the aquatic life. Treatment of wastewater is needed before its disposal. Activated carbon adsorption is one such method that has great potential for removing dyes from aqueous waste. The efficiency of adsorption of carbon-based materials like activated carbon depends on several factors, including the surface area, the distribution of the pore size, solution $\mathrm{pH}$, other ions in solution, and so on.

The most widely used activated carbons are microporous and have high surface areas, and as a consequence, they show high efficiency for the adsorption of low molecular weight compounds and larger molecules. Zhi-yuan carried out an adsorption study of methylene blue on activated carbon fiber (ACF) [11-18]. It has been used in adsorption systems, including removing noxious gases because of its extensive specific surface area, high adsorption capacity, well-developed microspores, reproducibility, and processability. Several effects of experimental parameters were tested, including the initial methylene blue (MB) concentration and the adsorption rates. Equilibrium data were fit well by a Freundlich isotherm equation. Adsorption measurement shows that the process is very fast. Nakagawa et al. attempted to evaluate the porous properties and hydrophobicity of activated carbons obtained from several solid wastes, namely, waste PET, waste tires, refuse-derived fuel, and wastes generated during lactic acid fermentation from the garbage. Activated carbons with various pore size distributions were obtained by the conventional steam-activation method via the pretreatment method (i.e., a mixture of raw materials with a metal salt, carbonization, and acid treatment before steam activation) [37-44].

Authors reported that the activated carbons with plentiful mesopores prepared from PET and waste tires had quite a high adsorption capacity for large molecules. Therefore, they are useful for wastewater treatment, especially for removing bulky adsorbates [14-20, 45-47]. 
Li et al. reported the displacement of atrazine by the strongly competing fraction of natural organic matter (NOM) in batch and continuous flow powdered activated carbon (PAC) adsorption system. During the combined hollow fiber membrane microfiltration operated in dead-end mode, it was found that membrane was effective for removing PAC particles from water suspensions and PAC tendency for irreversible membrane fouling was extremely low. The presented combined adsorption-membrane process has a potential application for organic dye removal [30-36, 49]. Tapered bed adsorption columns, using activated carbon, have been used by McKay et al. [22-28, 44-49]. Several other authors have also tested activated carbon for various dyes' adsorption [11-22, 31-37, 44-49]. Pereira et al. reported that the surface chemistry of a commercially activated carbon had been selectively modified without changing its textural properties significantly, employing chemical treatments. The results obtained confirmed through color removal from a real textile process effluent. [8-12, 22-26, 33-49].

\section{Materials and Methods}

\subsection{Materials.}

Chemicals were used as received without any modification or further steps of purification. The water hyacinth plant was procured from Giza on the west bank of the Nile River in Egypt. The plant's roots were removed, and only the stems and leaves were used in the experimentation process. The stems and leaves were meticulously washed and submerged in distilled water to ensure the removal of dirt and contaminants. The stems and leaves were subsequently dried in an oven at $100^{\circ} \mathrm{C}$ for 90 minutes. The dried stems and leaves were fragmented into smaller pieces and are permeated 3 times their weight with concentrated phosphoric acid $\left(\mathrm{H}_{3} \mathrm{PO} 4\right)$ at room temperature for 48 hours; $\mathrm{H}_{3} \mathrm{PO}_{4}$ was added to enhance the channels amongst the particles. The samples were then placed in a ceramic oven for 3 hours at a temperature of $600^{\circ} \mathrm{C}$ for carbonization to transpire.

The samples were left for 2 hours to cool down after ignition at room temperature. Afterward, the samples were washed with distilled water several times to ensure no remaining amounts of phosphoric acid were left. The samples were filtered and dried in an oven for 1 hour at a temperature of $110^{\circ} \mathrm{C}$. Lastly, the samples were finely ground into a delicate powder, as shown in Figure 1.

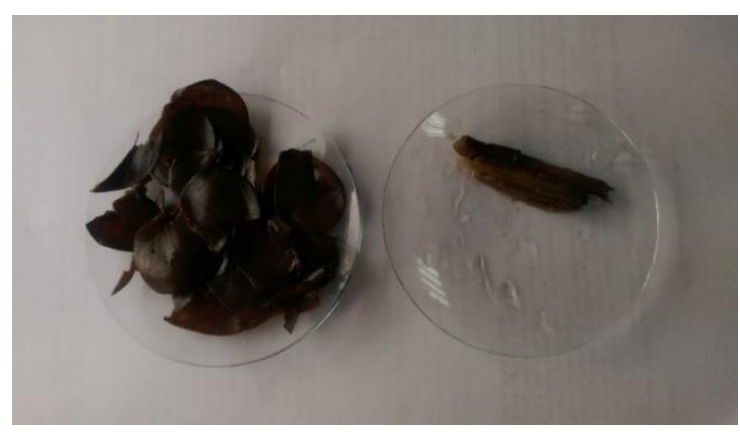

Figure 1. Water hyacinth after drying.

\subsection{Preparation of dye stock solutions.}

The obtained activated carbon, which amounted to $3.1 \mathrm{~g}$, was added to $200 \mathrm{ml}$ of distilled water and placed on a magnetic stirrer for 30 minutes at $450 \mathrm{rpm}$. After stirring, the cobalt metal salt was added to the solution and stirred for an additional 30 minutes. While stirring, 250- $\mu$ l of Hydrazine hydrate was added as a reducing agent to the solution. Afterward, 
the magnetic stirrer was taken out of the solution and placed in a microwave to be heated for 5 minutes at 10-second intervals to avert the solution from gushing out of the beaker. Henceforth, the solution was filtered and washed with water and ethanol and is left to dry overnight.

Methylene blue is a cationic compound that comprises crystals that exhibit a dark green hue, as shown in Figure 2. When dissolved in an aqueous solution, the sample manifests a deep blue color shown in Figure 3. The methylene blue used in experimentation is $82 \%$ pure. Three various dye concentrations were prepared, respectively, $4 \times 10^{-6} 6 \times 10^{-6}$ and $8 \times 10^{-6}$.

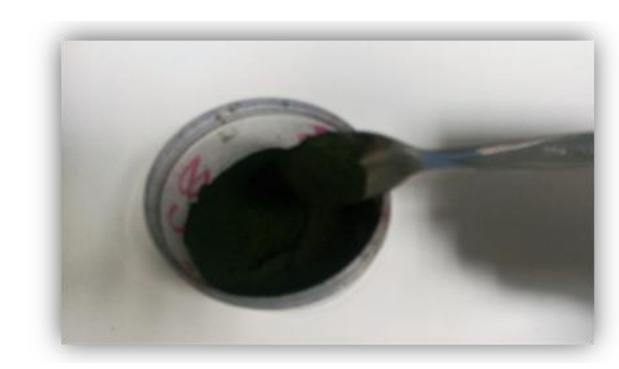

Figure 2. Methylene blue powder.

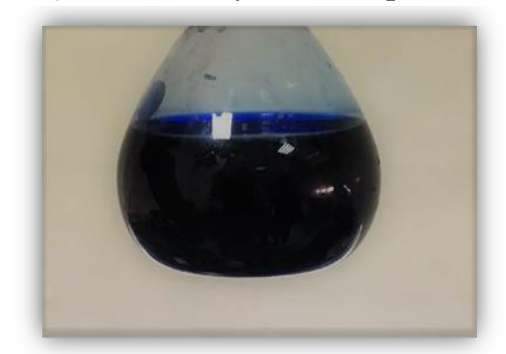

Figure 3. Methylene blue after the addition of water.

A UV/VIS spectrophotometer, as shown in Figure 4, was used to measure the absorbance of dye before and after the addition of activated carbon and activated nickel nanoparticles at a wavelength of 665. A UV/VIS spectrophotometer measures the absorbance of material on an ultraviolet region.

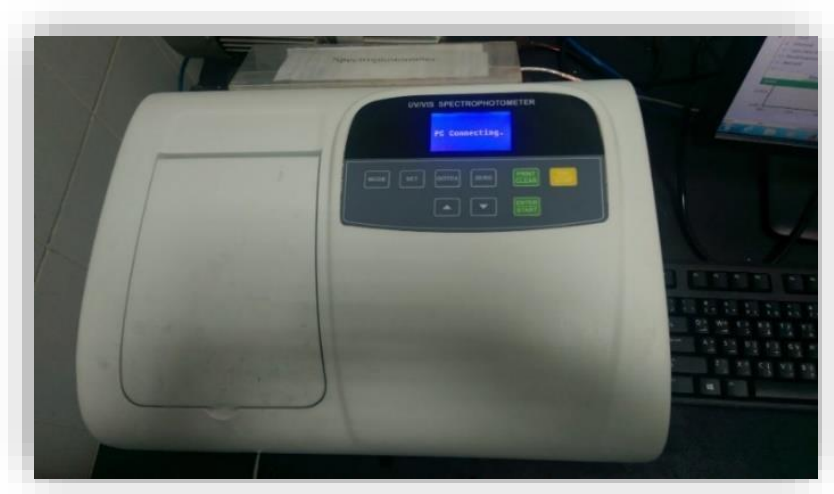

Figure 4. UV-vis spectrophotometer.

\section{Results and Discussion}

Table 1. Comparison between using activated carbon alone and with cobalt nanoparticles.

\begin{tabular}{l|l|l|l|l} 
Adsorbent & Tests & Initial concentration & Absorbance & Final concentration \\
\hline Water hyacinth & 1 minute shaking & $4 \times 10^{-6}$ & 0.0634 & $7.0455 \times 10^{-9}$ \\
\cline { 3 - 5 } activated carbon & & $6 \times 10^{-6}$ & 0.0639 & $7.0742 \times 10^{-9}$ \\
\cline { 3 - 5 } & $8 \times 10^{-6}$ & 0.0397 & $5.68 \times 10^{-9}$ \\
\cline { 2 - 5 } & \multirow{2}{*}{\begin{tabular}{l} 
shaking seconds \\
\cline { 2 - 5 }
\end{tabular}} & $4 \times 10^{-6}$ & 0.0668 & $7.241 \times 10^{-9}$ \\
\cline { 2 - 5 } & $6 \times 10^{-6}$ & 0.0889 & $8.511 \times 10^{-9}$ \\
\cline { 3 - 5 } & $8 \times 10^{-6}$ & 0.0781 & $7.890 \times 10^{-9}$ & 2700
\end{tabular}




\begin{tabular}{|c|c|c|c|c|}
\hline Adsorbent & Tests & Initial concentration & Absorbance & Final concentration \\
\hline & Instant contact & $4 \times 10^{-6}$ & 0.0391 & $5.648 \times 10^{-9}$ \\
\hline & & $6 \times 10^{-6}$ & 0.01148 & $1.0001 \times 10^{-8}$ \\
\hline & & $8 \times 10^{-6}$ & 0.0794 & $7.9655 \times 10^{-9}$ \\
\hline \multirow{9}{*}{$\begin{array}{l}\text { Water hyacinth } \\
\text { activated carbon with } \\
\text { cobalt nanoparticles }\end{array}$} & \multirow[t]{3}{*}{1 minute shaking } & $4 \times 10^{-6}$ & 0.0475 & $6.1312 \times 10^{-9}$ \\
\hline & & $6 \times 10^{-6}$ & 0.0862 & $8.3565 \times 10^{-9}$ \\
\hline & & $8 \times 10^{-6}$ & 0.0332 & $5.309 \times 10^{-9}$ \\
\hline & \multirow{3}{*}{$\begin{array}{ll}10 & \text { seconds } \\
\text { shaking } & \end{array}$} & $4 \times 10^{-6}$ & 0.0559 & $6.6142 \times 10^{-9}$ \\
\hline & & $6 \times 10^{-6}$ & 0.0658 & $7.1835 \times 10^{-3}$ \\
\hline & & $8 \times 10^{-6}$ & 0.0532 & $6.459 \times 10^{-9}$ \\
\hline & \multirow[t]{3}{*}{ Instant contact } & $4 \times 10^{-6}$ & 0.0565 & $6.6487 \times 10^{-9}$ \\
\hline & & $6 \times 10^{-6}$ & 0.0514 & $6.355 \times 10^{-9}$ \\
\hline & & $8 \times 10^{-6}$ & 0.0530 & $6.4475 \times 10^{-9}$ \\
\hline
\end{tabular}

Table 1 is typically summarizing and illustrating the values of absorbance projected from the UV/VIS spectrophotometer. Table 1 represents the values taken at wavelength 665 of the tests conducted with activated cobalt nanoparticles on three different dyes concentrations by adding $0.01 \mathrm{~g}$ activated cobalt nanoparticles on $30 \mathrm{ml}$ dye concentration. The aim is to test the effect of time and motion utilizing a mechanical shaker on both 1-minute and 10 seconds. It represents a comparative study between the same parameters of testing on activated carbon alone and using cobalt nanoparticles as well. It simply gives an overview of the impact of using different concentrations on absorbance. The effect of initial dye concentration was the first effect studied in this work. A series of dye solutions with $4 \times 10^{-6} \mathrm{M}, 6 \times 10^{-6} \mathrm{M}$, and $8 \times 10^{-6} \mathrm{M}$ initial dye concentrations were used in this study. It also illustrates the values of absorbance projected from the UV/VIS spectrophotometer. Results represent the values taken at wavelength 665 of the tests conducted with activated nickel nanoparticles on three different dyes concentrations by adding $0.005 \mathrm{~g}$ activated nickel nanoparticles on $30 \mathrm{ml}$ dye concentration. The aim is to test the effect of concentration and the extent of adsorption through funnel precipitation.

We investigated several series of the selected solutions with $4 \times 10^{-6} \mathrm{M}, 6 \times 10^{-6} \mathrm{M}$, and $8 \times 10^{-6} \mathrm{M}$ initial dye concentrations. This study has a different removal percentage. It was found that the carbon-based adsobent based on water hyacinth is the best and efficient concentration in removal percentage. However, increasing the concentration could not enhance the removal efficiency as it keeps decreasing until the minimum removal percentage was recorded.

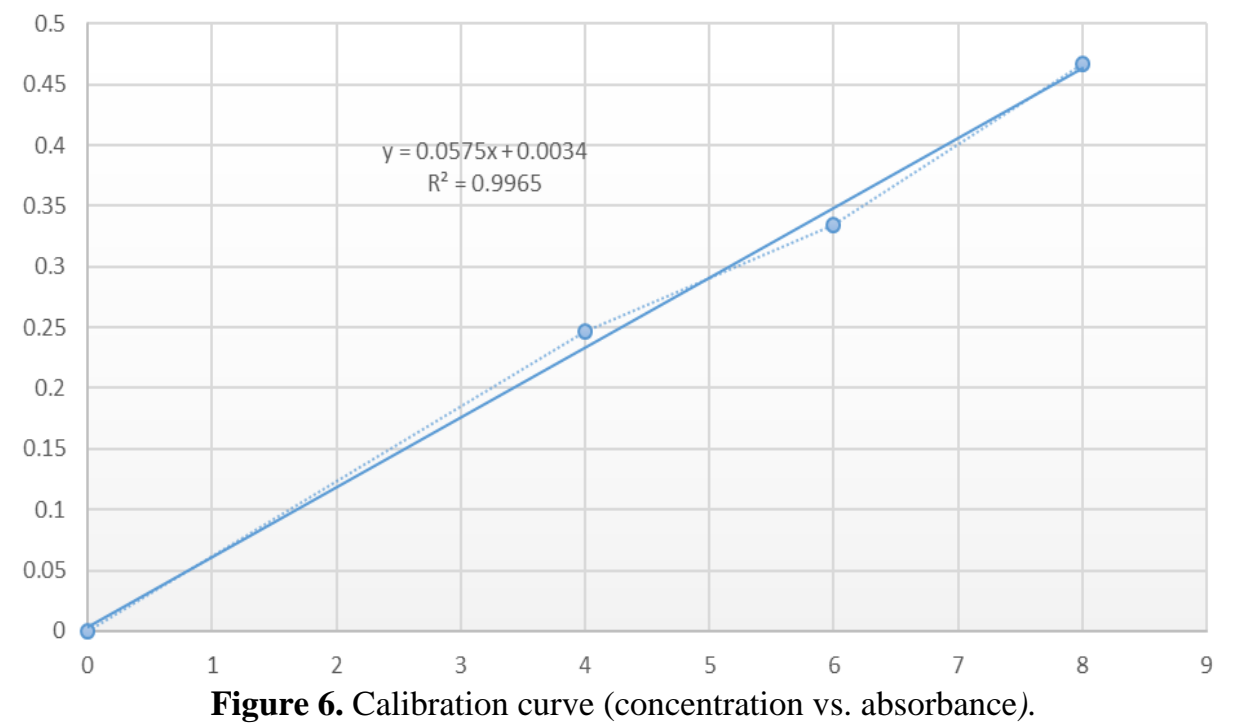


Based on the spectrophotometry results and mathematical calculations, it can be concluded that activated carbon is comparatively and highly efficient on its own in the removal of dye. The activated cobalt nanoparticles exhibit, more or less, the same adsorption percentage of activated carbon; this infers that nickel is not a highly efficient metal in the process of dye removal. Both activated carbon and activated cobalt nanoparticles were tested by adding 0.01 $\mathrm{g}$ on $30 \mathrm{ml}$ of different dye concentrations and subjected to mechanical shaking at a constant rpm of 150; once for 1 minute and once for 10 seconds. Furthermore, both activated carbon and activated nanoparticles were also tested by adding $0.005 \mathrm{~g}$ in a funnel and adding $30 \mathrm{ml}$ of dye. Experimentation was conducted by those means to establish the effect of kinetic motion on the rate of adsorption. It is concluded that kinetic energy has a relatively small effect on the degree of adsorption. The activated carbon and activated cobalt nanoparticles were highly potent in adsorbing the dye while being in a stationary or precipitation phase. Additionally, the effect of concentration was relatively negligible given that $0.005 \mathrm{~g}$ were able to absorb the same amount of dye as 0.01 .

\section{Conclusions}

In conclusion, by comparing activated cobalt nanoparticles and activated carbon, water hyacinth-derived activated carbon is highly successful and efficient in adsorbing methylene blue dye. On the other hand, to enhance the effectiveness and rate of absorbance of water hyacinth-derived activated carbon, further investigation of other metals, aside from cobalt, is needed to conclude a suitable metal oxide catalyst efficient enough to couple with the water hyacinth derived activated carbon.

\section{Funding}

This research was funded by The British University in EGYPT (BUE).

\section{Acknowledgments}

We express our deep gratitude to British University in Egypt (BUE). This work was partially performed using the facilities of the Nanotechnology Research Centre (NTRC) at the British University in Egypt (BUE).

\section{Conflicts of Interest}

The authors declare no conflict of interest.

\section{References}

1. Chen, S.; Si, R.; Taylor, E.; Janzen, J.; Chen, J. Synthesis of Pd/Fe3O4 Hybrid Nanocatalysts with Controllable Interface and Enhanced Catalytic Activities for CO Oxidation. The Journal of Physical Chemistry C 2012, 116, 12969-12976, https://doi.org/10.1021/jp3036204.

2. Radwan, N.R.E.; El-Shall, M.S.; Hassan, H.M.A. Synthesis and characterization of nanoparticle Co3O4, CuO and $\mathrm{NiO}$ catalysts prepared by physical and chemical methods to minimize air pollution. Applied Catalysis A: General 2007, 331, 8-18, https://doi.org/10.1016/j.apcata.2007.07.005.

3. Wang, H.; Casalongue, H.S.; Liang, Y.; Dai, H. Ni(OH)2 Nanoplates Grown on Graphene as Advanced Electrochemical Pseudocapacitor Materials. J. Am. Chem. Soc. 2010, 132, 7472-7477, https://doi.org/10.1021/ja102267j.

4. Wang, W.-W.; Zhu, Y.-J.; Ruan, M.-L. Microwave-assisted synthesis and magnetic property of magnetite and hematite nanoparticles. J. Nanopart. Res. 2007, 9, 419-426, https://doi.org/10.1007/s11051-005-9051-8. 
5. Elazab, H.A.; Moussa, S.; Gupton, B.F.; El-Shall, M.S. Microwave-assisted synthesis of Pd nanoparticles supported on $\mathrm{Fe} 3 \mathrm{O}$ 4, $\mathrm{Co} 3 \mathrm{O}$ 4, and $\mathrm{Ni}(\mathrm{OH}) 2$ nanoplates and catalysis application for $\mathrm{CO}$ oxidation. $J$. Nanopart. Res. 2014, 16, 1-11.

6. Radwan, M.A.; Al-Sweasy, O.H.; Elazab, H.A. Preparation of hydrogel based on acryl amide and investigation of different factors affecting rate and amount of absorbed water. Agricultural Sciences 2017, 8, 161, https://doi.org/10.4236/as.2017.82011.

7. Andrade, A.L.; Souza, D.M.; Pereira, M.C.; Fabris, J.D.; Domingues, R.Z. Catalytic Effect of Magnetic Nanoparticles Over the H2O2 Decomposition Reaction. Journal of Nanoscience and Nanotechnology 2009, 9, 3695-3699, https://doi.org/10.1166/jnn.2009.ns53.

8. Kustov, A.L.; Frey, A.M.; Larsen, K.E.; Johannessen, T.; Nørskov, J.K.; Christensen, C.H. CO methanation over supported bimetallic Ni-Fe catalysts: From computational studies towards catalyst optimization. Applied Catalysis A: General 2007, 320, 98-104, https://doi.org/10.1016/j.apcata.2006.12.017.

9. Lohitharn, N.; Goodwin, J.G. Impact of $\mathrm{Cr}, \mathrm{Mn}$ and $\mathrm{Zr}$ addition on Fe Fischer-Tropsch synthesis catalysis: Investigation at the active site level using SSITKA. J. Catal. 2008, 257, 142-151, https://doi.org/10.1016/j.jcat.2008.04.015.

10. Moreau, F.; Bond, G.C. CO oxidation activity of gold catalysts supported on various oxides and their improvement by inclusion of an iron component. Catal. Today 2006, 114, 362-368, https://doi.org/10.1016/j.cattod.2006.02.074.

11. Sarkari, M.; Fazlollahi, F.; Atashi, H.; Mirzaei, A.A.; Hosseinpour, V. Fischer-Tropsch synthesis: Development of kinetic expression for a sol-gel Fe-Ni/Al2O3 catalyst. Fuel Process. Technol. 2012, 97, 130-139, https://doi.org/10.1016/j.fuproc.2012.01.008.

12. Elazab, H.A.; Moussa, S.; Siamaki, A.R.; Gupton, B.F.; El-Shall, M.S. The Effect of Graphene on Catalytic Performance of Palladium Nanoparticles Decorated with Fe3O4, Co3O4, and Ni (OH)2: Potential Efficient Catalysts Used for Suzuki Cross-Coupling. Catal. Lett. 2017, 147, 1510-1522, https://doi.org/10.1007/s10562-017-1990-z.

13. Elazab, H.A.; Moussa, S.; Brinkley, K.W.; Gupton, B.F.; El-Shall, M.S. The continuous synthesis of Pd supported on $\mathrm{Fe} 3 \mathrm{O} 4$ nanoparticles: a highly effective and magnetic catalyst for $\mathrm{CO}$ oxidation. Green Processing and Synthesis 2017, 6, 413-424, https://doi.org/10.1515/gps-2016-0168.

14. Elazab, H.A.; Sadek, M.A.; El-Idreesy, T.T. Microwave-assisted synthesis of palladium nanoparticles supported on copper oxide in aqueous medium as an efficient catalyst for Suzuki cross-coupling reaction. Adsorption Science \& Technology 2018, 36, 1352-1365, https://doi.org/10.1177/0263617418771777.

15. Elazab, H.A.; Siamaki, A.R.; Moussa, S.; Gupton, B.F.; El-Shall, M.S. Highly efficient and magnetically recyclable graphene-supported $\mathrm{Pd} / \mathrm{Fe} 3 \mathrm{O} 4$ nanoparticle catalysts for Suzuki and Heck cross-coupling reactions. Applied Catalysis A: General 2015, 491, 58-69, https://doi.org/10.1016/j.apcata.2014.11.033.

16. Hirvi, J.T.; Kinnunen, T.-J.J.; Suvanto, M.; Pakkanen, T.A.; Nørskov, J.K. CO oxidation on PdO surfaces. The Journal of Chemical Physics 2010, 133, 084704, https://doi.org/10.1063/1.3464481.

17. Iglesias-Juez, A.; Kubacka, A.; Fernández-García, M.; Di Michiel, M.; Newton, M.A. Nanoparticulate Pd Supported Catalysts: Size-Dependent Formation of $\mathrm{Pd}(\mathrm{I}) / \mathrm{Pd}(0)$ and Their Role in CO Elimination. J. Am. Chem. Soc. 2011, 133, 4484-4489, https://doi.org/10.1021/ja110320y.

18. Ivanova, A.S.; Slavinskaya, E.M.; Gulyaev, R.V.; Zaikovskii, V.I.; Stonkus, O.A.; Danilova, I.G.; Plyasova, L.M.; Polukhina, I.A.; Boronin, A.I. Metal-support interactions in Pt/Al2O3 and Pd/Al2O3 catalysts for CO oxidation. Applied Catalysis B: $\quad$ Environmental $2010, \quad 97, \quad 57-71$, https://doi.org/10.1016/j.apcatb.2010.03.024.

19. Chattopadhyay, K.; Dey, R.; Ranu, B.C. Shape-dependent catalytic activity of copper oxide-supported $\operatorname{Pd}(0)$ nanoparticles for Suzuki and cyanation reactions. Tetrahedron Lett. 2009, 50, 3164-3167, https://doi.org/10.1016/j.tetlet.2009.01.027.

20. Hoseini, S.J.; Habib Agahi, B.; Samadi Fard, Z.; Hashemi Fath, R.; Bahrami, M. Modification of palladiumcopper thin film by reduced graphene oxide or platinum as catalyst for Suzuki-Miyaura reactions. Appl. Organomet. Chem. 2017, 31, e3607, https://doi.org/10.1002/aoc.3607.

21. Hosseini-Sarvari, M.; Razmi, Z. Palladium Supported on Zinc Oxide Nanoparticles as Efficient Heterogeneous Catalyst for Suzuki Miyaura and Hiyama Reactions under Normal Laboratory Conditions. Helv. Chim. Acta 2015, 98, 805-818, https://doi.org/10.1002/hlca.201400331.

22. Nasrollahzadeh, M.; Jaleh, B.; Ehsani, A. Preparation of carbon supported CuPd nanoparticles as novel heterogeneous catalysts for the reduction of nitroarenes and the phosphine-free Suzuki-Miyaura coupling reaction. New J. Chem. 2015, 39, 1148-1153, https://doi.org/10.1039/C4NJ01788A. 
23. Nasrollahzadeh, M.; Sajadi, S.M.; Rostami-Vartooni, A.; Azarian, A. Palladium nanoparticles supported on copper oxide as an efficient and recyclable catalyst for carbon(sp2)-carbon(sp2) cross-coupling reaction. Mater. Res. Bull. 2015, 68, 150-154, https://doi.org/10.1016/j.materresbull.2015.03.051.

24. Mandali, P.K.; Chand, D.K. Palladium nanoparticles catalyzed Suzuki cross-coupling reactions in ambient conditions. Catal. Commun. 2013, 31, 16-20, https://doi.org/10.1016/j.catcom.2012.10.020.

25. Wang, Y.; Wen, Z.; Zhang, H.; Cao, G.; Sun, Q.; Cao, J. CuO Nanorods-Decorated Reduced Graphene Oxide Nanocatalysts for Catalytic Oxidation of CO. Catalysts 2016, 6, https://doi.org/10.3390/catal6120214.

26. Igarashi, H.; Uchida, H.; Watanabe, M. Mordenite-Supported Noble Metal Catalysts for Selective Oxidation of Carbon Monoxide in a Reformed Gas. Chem. Lett. 2000, 29, 1262-1263, https://doi.org/10.1246/cl.2000.1262.

27. Liu, W.H.; Fleming, S.; Lairson, B.M. Reduced intergranular magnetic coupling in Pd/Co multilayers. $J$. Appl. Phys. 1996, 79, 3651-3655, https://doi.org/10.1063/1.361193.

28. Luo, J.-Y.; Meng, M.; Li, X.; Li, X.-G.; Zha, Y.-Q.; Hu, T.-D.; Xie, Y.-N.; Zhang, J. Mesoporous Co3O4$\mathrm{CeO} 2$ and $\mathrm{Pd} / \mathrm{Co} 3 \mathrm{O} 4-\mathrm{CeO} 2$ catalysts: Synthesis, characterization and mechanistic study of their catalytic properties for low-temperature CO oxidation. J. Catal. 2008, 254, 310-324, https://doi.org/10.1016/j.jcat.2008.01.007.

29. Pavlova, S.N.; Sadykov, V.A.; Bulgakov, N.N.; Bredikhin, M.N. The Influence of Support on the LowTemperature Activity of Pd in the Reaction of CO Oxidation: 3. Kinetics and Mechanism of the Reaction. $J$. Catal. 1996, 161, 517-523, https://doi.org/10.1006/jcat.1996.0213.

30. Diyarbakir, S.; Can, H.; Metin, Ö. Reduced Graphene Oxide-Supported CuPd Alloy Nanoparticles as Efficient Catalysts for the Sonogashira Cross-Coupling Reactions. ACS Applied Materials \& Interfaces 2015, 7, 3199-3206, https://doi.org/10.1021/am507764u.

31. Feng, Y.-S.; Ma, J.-J.; Kang, Y.-M.; Xu, H.-J. PdCu nanoparticles supported on graphene: an efficient and recyclable catalyst for reduction of nitroarenes. Tetrahedron 2014, 70, 6100-6105, https://doi.org/10.1016/j.tet.2014.04.034.

32. Liu, Y.; Ma, H.; Gao, J.; Wu, D.; Ren, X.; Yan, T.; Pang, X.; Wei, Q. Ultrasensitive electrochemical immunosensor for SCCA detection based on ternary $\mathrm{Pt} / \mathrm{PdCu}$ nanocube anchored on three-dimensional graphene framework for signal amplification. Biosensors Bioelectron. 2016, 79, 71-78, https://doi.org/10.1016/j.bios.2015.12.013.

33. Shafaei Douk, A.; Saravani, H.; Noroozifar, M. Novel fabrication of PdCu nanostructures decorated on graphene as excellent electrocatalyst toward ethanol oxidation. Int. J. Hydrogen Energy 2017, 42, 1514915159, https://doi.org/10.1016/j.ijhydene.2017.04.280.

34. Elazab, H.A. Investigation of microwave-assisted synthesis of palladium nanoparticles supported on Fe3O4 as efficient recyclable magnetic catalysts for Suzuki-Miyaura cross-coupling. The Canadian Journal of Chemical Engineering 2019, 97, 1545-1551, https://doi.org/10.1002/cjce.23402.

35. Radwan, M.A.; Al-Sweasy, O.; Sadek, M.A.; Elazab, H.A. Investigating the Agricultural Applications of Acryl Amide based Hydrogel. International Journal of Engineering and Technology (UAE) 2018, 7, 168171, https://doi.org/10.14419/ijet.v7i4.29.21711.

36. Zakaria, F.; Radwan, M.A.; Sadek, M.A.; Elazab, H.A. Insulating material based on shredded used tires and inexpensive polymers for different roofs. International Journal of Engineering and Technology (UAE) 2018, 7, 1983-1988, https://doi.org/10.14419/ijet.v7i4.14081.

37. Nasser, R.; Radwan, M.A.; Sadek, M.A.; Elazab, H.A. Preparation of insulating material based on rice straw and inexpensive polymers for different roofs. International Journal of Engineering and Technology (UAE) 2018, 7, 1989-1994, https://doi.org/10.14419/ijet.v7i4.14082.

38. Ghobashy, M.; Gadallah, M.; El-Idreesy, T.T.; Sadek, M.A.; Elazab, H.A. Kinetic study of hydrolysis of ethyl acetate using caustic soda. Journal of Engineering and Technology (UAE) 2018, 7, 1995-1999, https://doi.org/10.14419/ijet.v7i4.14083.

39. Samir, N.; Radwan, M.; Sadek, M.; Elazab, H.J.I.j.o.e.; technology. Preparation and characterization of bullet-proof vests based on polyamide fibers. 2018, 7, 1290.

40. Ashraf, B.; Radwan, M.A.; Sadek, M.A.; Elazab, H.A. Preparation and characterization of decorative and heat insulating floor tiles for buildings roofs. International Journal of Engineering and Technology (UAE) 2018, 7, 1295-1298, https://doi.org/10.14419/ijet.v7i3.13177.

41. Radwan, M.A.; Rashad, M.A.; Sadek, M.A.; Elazab, H.A. synthesis, characterization and selected application of chitosan-coated magnetic iron oxide nanoparticles. Journal of Chemical Technology \& Metallurgy 2019, 54. 
42. Abdelhady, H.H.; Elazab, H.A.; Ewais, E.M.; Saber, M.; El-Deab, M.S. Efficient catalytic production of biodiesel using nano-sized sugar beet agro-industrial waste. Fuel 2020, 261, 116481, https://doi.org/10.1016/j.fuel.2019.116481.

43. Elazab, H.; Sadek, M.; El-Idreesy, T. Facile synthesis of reduced graphene oxide-supported $\mathrm{Pd} / \mathrm{CuO}$ nanoparticles as an efficient catalyst for cross-coupling reactions. 2019, 54, 934-946.

44. Elazab, H.A.; El-Idreesy, T.T. Polyvinylpyrrolidone-Reduced Graphene Oxide-Pd Nanoparticles as an Efficient Nanocomposite for Catalysis Applications in Cross-Coupling Reactions. Bulletin of Chemical Reaction Engineering and Catalysis 2019, 14, 490-501, https://doi.org/10.9767/bcrec.14.3.3461.490-501.

45. Elazab, H.A.; Siamaki, A.R.; Gupton, B.F.; El-Shall, M.S. Pd-Fe3O4/RGO: a Highly Active and Magnetically Recyclable Catalyst for Suzuki Cross Coupling Reaction using a Microfluidic Flow Reactor. Bulletin of Chemical Reaction Engineering and Catalysis 2019, 14, 478-489, https://doi.org/10.9767/bcrec.14.3.3518.478-489.

46. Elazab, H.A.; Radwan, M.A.; El-Idreesy, T.T. Facile Microwave-Assisted Synthetic Approach to Palladium Nanoparticles Supported on Copper Oxide as an Efficient Catalyst for Heck and Sonogashira Cross-Coupling Reactions. International Journal of Nanoscience $\mathbf{2 0 1 8 ,} \quad 18, \quad 1850032$, https://doi.org/10.1142/S0219581X18500321.

47. Elazab, H.A.; Radwan, M.A.; Sadek, M.A. Microwave-assisted Synthesis of Graphene supported Hexagonal Magnetite for Applications in Catalysis. International Journal of Innovative Technology and Exploring Engineering (IJITEE) 2019, 8, 5511-5513.

48. Aboul-Fotouh, T.M.; Ibrahim, S.K.; Sadek, M.A.; Elazab, H.A. High Octane Number Gasoline-Ether Blend. International Journal of Innovative Technology and Exploring Engineering (IJITEE) 2019, 8, 9, https://doi.org/10.35940/ijitee.F3610.078919.

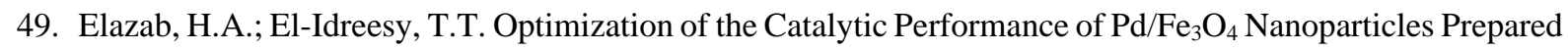
via Microwave-assisted Synthesis for Pharmaceutical and Catalysis Applications. Biointerface Research in Applied Chemistry 2019, 9, 3794-3799, https://doi.org/10.33263/BRIAC91.794799. 